\title{
Impact Synchronous Electromagnetic Machines Forced Cooling Systems Constructions Estimation
}

\author{
Vladimir Y. Neyman and Ludmila A. Neyman* \\ Novosibirsk State Technical University \\ 20 Karl Marx Avenue, Novosibirsk, 630073, Russia
}

Received 12.11.2014, received in revised form 20.01.2015, accepted 16.02.2015

\begin{abstract}
Impact synchronous electromagnetic machines forced cooling systems constructions have been classified and estimated.

The first group of electromagnetic machines cooling systems include impact node external ventilation ones where heat is dissipated only from the magnetic core external cylinder surface. The second group involves cooling systems with internal airflow paths having independent air inlet and outlet through holes in poles. The third group includes cooling systems with coaxial channels in windings. If multilayer winding separate sections have the same thickness, their balancing cooling is provided by airflow rate in particular ventilation channels in proportion to dissipated power. Hence temperature difference between heated layers in the winding space can be two times and more reduced. The fourth group includes cooling systems with channels radial configuration to increase windings total cooling surface area, reduce airflow resistance and provide more balanced heating of both windings.

External forced airflow cooling systems are specified with heat flow range related to winding cooling surface area and specific winding active volume thermal load.

Forced air cooling is proved to permit additional electromagnetic impact load, increasing impact energy or frequency at permissible heating. Ventilation unit power to support electromagnetic impact machine duty cycle about $100 \%$ can be $25 \%$ of power consumed by the impact node.
\end{abstract}

Keywords:impact electrical machines; synchronous electromagnetic machines; electromagnetic motor; air cooling systems; impact energy; consumed power; losses power; heat flow; specific thermal load.

(C) Siberian Federal University. All rights reserved

* Corresponding author E-mail address: neyman@ngs.ru 


\title{
Оценка конструктивного совершенства
}

\author{
систем принудительного охлаждения \\ синхронных электромагнитных машин \\ ударного действия
}

\author{
В.Ю. Нейман, Л.А. Нейман \\ Новосибирский государственный технический университет \\ Россия, 630073, Новосибирск, пр. К. Маркса, 20
}

\begin{abstract}
В проводимых исследованиях выполнена классификация и дана оценка конструктивного совершенства систем принудительного воздушного охлаждения синхронных электромагнитных машин ударного действия.

$K$ первой группе признаков систем охлаждения отнесены электромагнитные мамины с наружной вентиляцией ударного узла, в которых теплоотдача осуществляется только с внешней иилиндрической поверхности магнитопровода. Ко второй группе признаков отнесены системы охлаждения с внутренними воздушными трактами с автономным вводом и выводом воздуха через отверстия в полюсах. К третьей группе - системы охлаждения с коаксиальными каналами в катушках. Равномерность охлаждения отдельных секиий многослойной катушки при одинаковой их толщине, обеспечиваемая расходом воздуха в отдельных вентиляиионных каналах пропориионально с выделяемой в них мощностью, позволяет в два и более раз снизить разнииу температур в нагретых слоях обмоточного пространства. К четвертой группе признаков отнесены системы охлаждения с радиальным расположением каналов, позволяющие увеличить общую площадь охлаждения катушек, снизить сопротивление воздушному потоку и обеспечить более равномерный нагрев обеих катушек.

Для систем с принудительным воздушным охлаждением установлены предель изменения значений теплового потока, отнесенного к поверхности охлаждения катушки, и удельной тепловой нагрузки активного объема, занятого катушкой.

Показано, что принудительное воздушное охлаждение позволяет дополнительно нагрузить электромагнитный ударный узел и тем самым повысить энергию или частоту удара при допустимом нагреве. Для поддержания режима работы электромагнитной ударной машины с ПВ $=100 \%$ мощность вентиляционной установки может составлять до $25 \%$ от мощности, потребляемой ударным узлом.
\end{abstract}

Ключевые слова: электрические машины ударного действия, синхронные электромагнитные машины, электромагнитный двигатель, системы воздушного охлаждения, энергия удара, потребляемая мощчность, мощчность потерь, тепловой поток, удельная тепловая нагрузка.

\section{1. Введение}

Созданные в последнее время конструкции линейных электромагнитных двигателей ударного действия определили ряд новых конструктивных решений систем охлаждения, определяющих интенсификацию теплоотдачи и продолжительность рабочего режима ударного узла.

Результаты исследований и оценка конструктивного совершенства синхронных электромагнитных машин ударного действия показали, что в соответствии с требованиями, предъявляемыми к ударной нагрузке, ни одна из этих машин при естественным воздушном охлаждении не удовлетворяет условиям работы с ПВ = 100 \% [1]. Сокращение продолжительности 
включения до ПВ $=60,40,25$ и 15 \% позволяет дополнительно нагрузить электромагнитный узел и тем самым повысить единичную энергию удара при допустимом нагреве, что обусловливает увеличение не только потребляемой машиной мощности, но и колебания температуры [2-5].

Длительный режим работы электромагнитных ударных узлов таких машин может быть обеспечен только за счет повышения интенсивности теплоотдачи с поверхности катушек.

\section{2. Постановка задачи и ее решение}

В качестве критерия для сравнения теплооддаюих способностей существующих систем охлаждения используется понятие поверхностной плотности теплового потока, представляющей собой отношение допустимой мощности тепловыделения (тепловых потерь) $Q$ в катушке к поверхности ее охлаждения $S_{\mathrm{K}}$ :

$$
q_{S}=\frac{Q}{S_{\mathrm{K}}},
$$

где $q_{s}$ - допустимая плотность теплового потока, $\mathrm{BT} / \mathrm{M}^{2} ; Q$ - допустимая мощность тепловыделения катушки (тепловой поток), Вт; $S_{\text {K }}$ поверхность охлаждения катушки, м²

Мощность тепловыделения (мощность отводимых потерь), как известно, определяется выражением

$$
Q=P_{\Pi}=k_{\mathrm{T}} S_{\mathrm{K}} \tau,
$$

где $k_{\mathrm{T}}$ - коэффициент теплоотдачи, Вт/м²; $\tau$ - превышение температуры поверхности над температурой окружающей среды (перегрев), ${ }^{\circ} \mathrm{C} ; P_{\Pi}-$ тепловые потери в катушке, Вт.

Следовательно, поверхностную плотность теплового потока можно представить как

$$
q_{s}=k_{\mathrm{T}} \tau
$$

Следует заметить, что при допустимом превышении температуры в пределах $\tau=80 \ldots 140{ }^{\circ} \mathrm{C}$ для многослойных катушек по ГОСТ 12434-83 с изоляционными материалами и нагревостойкостью по ГОСТ 8865-93 допустимая плотность теплового потока при естественном воздушном охлаждении может составлять $q=800 \ldots 2100 \mathrm{BT} / \mathrm{M}^{2}[2]$.

В существующих системах принудительного охлаждения ударных узлов коэффициент теплоотдачи для скорости воздуха в пределах $10 \ldots 40 \mathrm{~m} / \mathrm{c}$ составляет $k_{\mathrm{T}}=50 \ldots 130 \mathrm{BT} / \mathrm{M}^{2} \cdot{ }^{\circ} \mathrm{C}$, а допустимая плотность потока рекомендуется в интервале $5 \ldots 10 \mathrm{BT} / \mathrm{M}^{2}$, что почти на порядок выше, чем при естественном охлаждении [6-8].

Выбор той или иной схемы принудительного охлаждения предопределяется рядом факторов, основными из которых являются режим работы ударного узла и энергетические показатели [9].

Наибольшее распространение среди созданных электромагнитных машин ударного действия получило принудительное воздушное охлаждение. В последовательности совершенствования можно выделить четыре основные группы конструктивных признаков существующих систем охлаждения. Варианты конструктивных схем в продольном и поперечном разрезах приведены на рис. 1-5. 

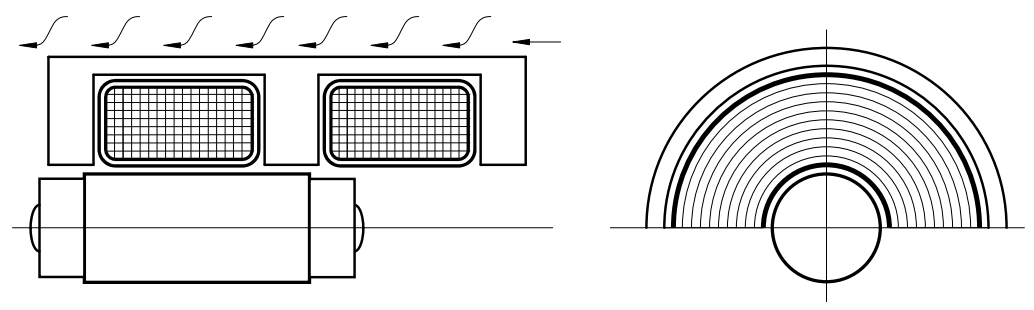

Рис. 1. Система охлаждения с наружной вентиляцией цилиндрической поверхности магнитопровода
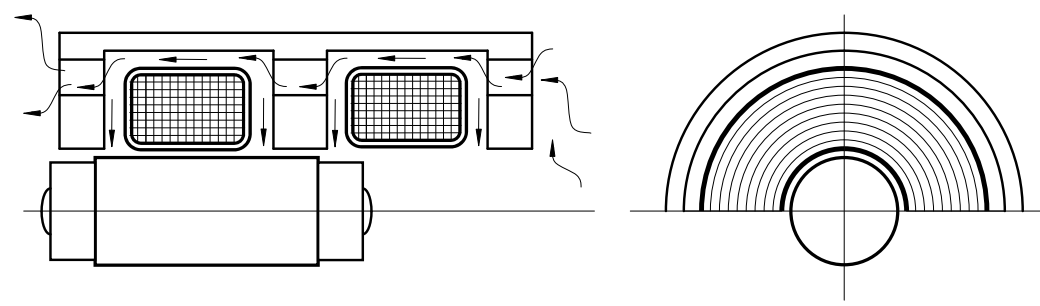

Рис. 2. Система охлаждения с воздушными трактами
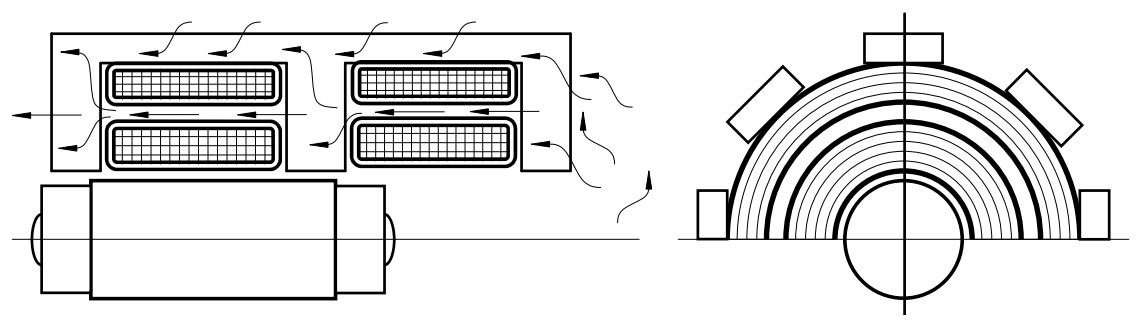

Рис. 3. Система охлаждения с коаксиальными каналами в катушке

К первой группе признаков систем с принудительным воздушным охлаждением следует отнести электромагнитные машины с наружной вентиляцией двигателя (рис. 1) [10 -12]. Теплоотдача в этом случае происходит с внешней цилиндрической поверхности магнитопровода, что по сравнению с естественной системой охлаждения позволяет существенно повысить коэффициент теплоотдачи.

Результаты тепловых испытаний электромагнитного ударного узла показали, что при увеличении расхода охлаждающего воздуха с 20 до 50 м³/ч по отношению к естественному способу охлаждения позволяет увеличить допустимую мощность потерь соответственно в 1,6...2,3 раза [9]. При этом мощность, расходуемая на вентиляцию, в среднем составляет 0,33 Вт на каждый ватт отводимой мощности потерь.

Наружная вентиляция ударного узла была опробована при производстве двухкатушечной электромагнитной машины СЦ-2 с энергией удара 4 Дж. При потреблении ударным узлом мощности 580 Вт продолжительность включения составила ПВ $=25 \%$ [9]. Тепловые испытания показали разницу средней температуры нагрева катушки и магнитопровода, равную $64^{\circ} \mathrm{C}$. 

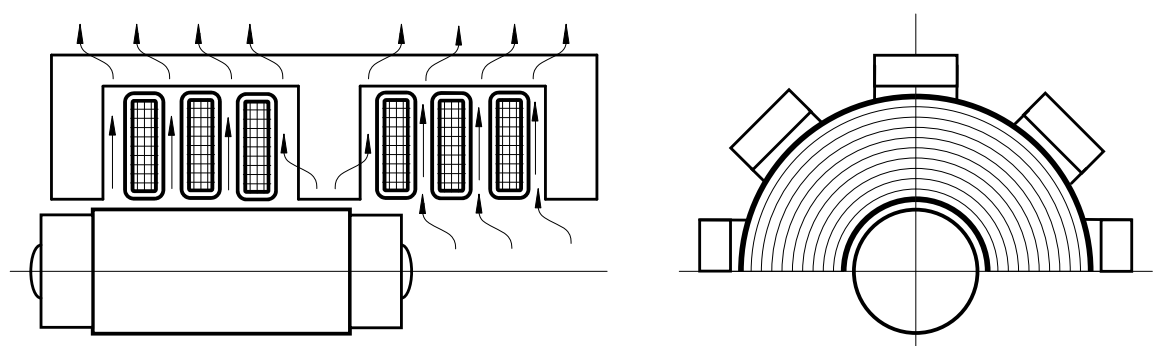

Рис. 4. Система охлаждения с радиальным расположением каналов в катушке
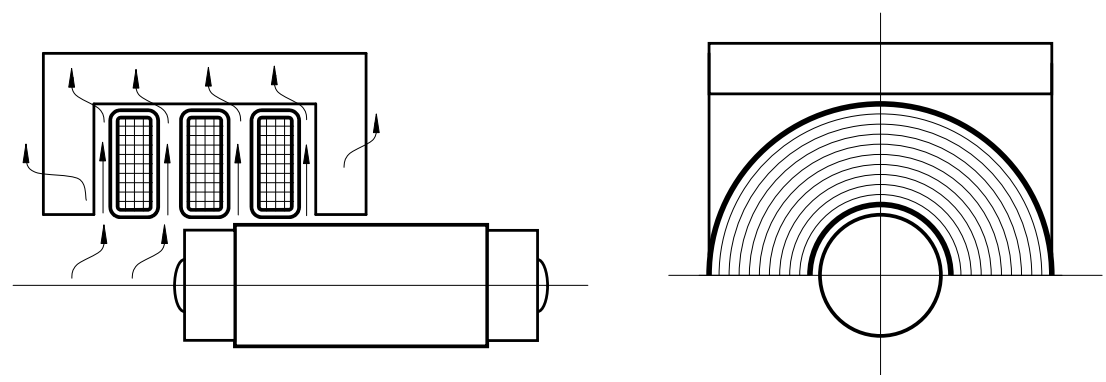

Рис. 5. Система охлаждения с радиальным расположением каналов в катушке и прямоугольным магнитопроводом

Из-за значительных градиентов температур внутри ударного узла, а также высоких затрат энергии на вентиляцию данная система охлаждения не получила широкого практического применения.

Ко второй группе признаков электромагнитных машин с принудительной вентиляцией катушек следует отнести системы охлаждения, приведенные на рис. 2. Выполнение специальных вентиляционных отверстий в конструкции двигателя позволило создать воздушные тракты, образованные цилиндрическими и торцевыми плоскостями обмоток и магнитопроводом с автономным вводом и выводом воздуха через отверстия в полюсах. Условия формирования аэродинамического режима непосредственно связаны с геометрическими характеристиками вентиляционной системы.

Интенсификация процесса теплоотдачи здесь заметно повышается и при ПВ $=100$ \% система с непосредственной вентиляцией катушек позволяет отводить в 1,6 раза больше мощности потерь, чем система с наружной вентиляцией ударного узла.

При расходе охлаждающего воздуха в пределах $20 \ldots 50$ м³/ч мощность, расходуемая на вентиляцию, составляет в среднем 0,2 Вт на каждый ватт отводимой от ударного узла мощности потерь [9]. Интенсификация процесса теплоотдачи в сравнении с естественным воздушным охлаждением здесь заметно повышается так, как в несколько раз может быть увеличен коэффициент теплоотдачи.

К недостаткам системы охлаждения следует в первую очередь отнести большую разницу между более и менее нагретыми слоями обмоточного пространства. Именно по этой причине данная система охлаждения не получила широкого распространения и была ограничена в сво-

$$
-170-
$$


ем использовании на уровне опытно-конструкторских разработок синхронных электромагнитных ударных узлов с энергией удара до 20 Дж.

К третьей группе, получившей наибольшее признание, следует отнести системы вентиляции с коаксиальными каналами в катушках (рис. 3). Равномерность охлаждения отдельных секций многослойной катушки при одинаковой их толщине стала возможной за счет расхода воздуха в отдельных вентиляционных каналах пропорционально с выделяемой в них мощностью.

Данная система вентиляции впервые была опробована в 1974 г. при серийном производстве электромагнитной ударной машины ИЭ-4207, рассчитанной на энергию удара 4,5 Дж и имеющей полезную мощность ударного узла, равную 225 Вт. По данной схеме охлаждения также были выполнены серийно производимые ударные узлы электромагнитных машин ИЭ4210, ИЭ-4709 с полезной мощностью 315 и 125 Вт соответственно [13-15].

Достоинством данной системы охлаждения признано то, что разделение объема катушки на ряд секций, изолированных друг от друга воздушными коаксиальными каналами, позволяет в два и более раз снизить разницу температур в нагретых слоях обмоточного пространства. Одним из главным недостатков используемого принципа охлаждения является более низкий коэффициент заполнения катушки.

Вынужденное движение воздушного потока связано с потерями на трение, пропорциональными длине вентиляционного канала, что оказывает влияние на теплообмен. Например, для двухкатушечных электромагнитных машин разница в средней температуре перегрева между катушками (прямого и обратного) может составлять до $30 \%$.

Дальнейшее совершенствование интенсификации процесса теплоотдачи нашло свое отражение в системах охлаждения, относящихся к четвертой группе признаков (рис. 4, 5).

Системы вентиляции с радиальным расположением каналов позволили увеличить общую площадь охлаждения катушек, снизить сопротивление воздушному потоку и обеспечить более равномерный нагрев обеих катушек.

По принципу охлаждения на рис. 4 была разработана вентиляционная система двухкатушечной электромагнитной машины ИЭ-4724 с полезной мощностью ударного узла 125 Вт. По принципу охлаждения на рис. 5 разрабатывалась вентиляционная система однокатушечной электромагнитной машины Т-312 с максимальной энергией удара 3 Дж и максимальной полезной мощностью ударного узла 75 Вт.

Поиск рациональной системы охлаждения, прежде всего, связан со структурной схемой электромагнитной ударной машины, которая определяет конструкцию и компоновку всей машины. Сравнительная оценка достигнутого уровня совершенства используемых систем охлаждения синхронных электромагнитных машин ударного действия с принудительным воздушным охлаждением представлена в табл. 1.

В качестве критериев, отражающих совокупность определенных качеств и условий работы, рассматриваемых систем введены дополнительные показатели.

Для характеристики теплонапряженности электромагнитной машины введем показатель удельной тепловой нагрузки катушки, представляющий собой отношение мощности потерь в катушке $Q$ к объему активных материалов катушки $V_{\mathrm{M}}$ 
Таблица 1. Показатели систем принудительного воздушного охлаждения синхронных электромагнитных машин ударного действия

\begin{tabular}{|c|c|c|c|c|c|c|c|}
\hline $\begin{array}{c}\text { № } \\
\Pi / \Pi\end{array}$ & Наименование величин & 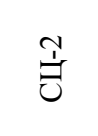 & 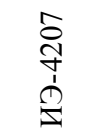 & 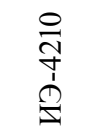 & 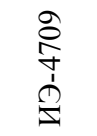 & 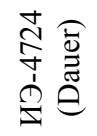 & 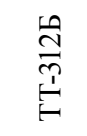 \\
\hline 1 & Энергия удара, Дж & 4,0 & 4,5 & 6,3 & 2,5 & 2,5 & 2,1 \\
\hline 2 & Количество ударов, уд/мин & 3000 & 3000 & 3000 & 3000 & 3000 & 2000 \\
\hline 3 & $\begin{array}{l}\text { Мощность, потребляемая ударным узлом, } \\
\text { Вт }\end{array}$ & 580 & 600 & 700 & 400 & 400 & 250 \\
\hline 4 & Полезная мощность, Вт & 200 & 225 & 315 & 125 & 125 & 70 \\
\hline 5 & Мощность потерь (тепловой поток), Вт & 380 & 375 & 385 & 275 & 275 & 180 \\
\hline 6 & КПД, \% & 35 & 37,5 & 45 & 31 & 31 & 28 \\
\hline 7 & $\Pi В, \%$ & 25 & 60 & 60 & 100 & 100 & 100 \\
\hline 8 & $\begin{array}{l}\text { Масса катушки, кг: } \\
\text { - прямого хода } \\
\text { - обратного хода }\end{array}$ & $\begin{array}{l}0,59 \\
0,59\end{array}$ & $\begin{array}{l}0,42 \\
0,58\end{array}$ & $\begin{array}{l}0,42 \\
0,58\end{array}$ & $\begin{array}{l}0,48 \\
0,48\end{array}$ & $\begin{array}{l}0,35 \\
0,35\end{array}$ & $\begin{array}{c}0,19 \\
-\end{array}$ \\
\hline 9 & $\begin{array}{l}\text { Поверхность охлаждения катушки, } \times 10^{-4} \text { м: } \\
\text { - прямого хода: } \\
\text { - обратного хода: }\end{array}$ & $\begin{array}{l}76,9 \\
76,9 \\
\end{array}$ & $\begin{array}{l}162,1 \\
224,2 \\
\end{array}$ & $\begin{array}{l}162,1 \\
224,2 \\
\end{array}$ & $\begin{array}{l}171,5 \\
171,5\end{array}$ & $\begin{array}{l}212,6 \\
212,6\end{array}$ & $\begin{array}{c}116,7 \\
-\end{array}$ \\
\hline 10 & $\begin{array}{l}\text { Объём катушки, } \times 10^{-6} \mathrm{M}^{3}: \\
\quad \text { - прямого хода } \\
\text { - обратного хода }\end{array}$ & $\begin{array}{l}109,9 \\
109,9\end{array}$ & $\begin{array}{c}78,6 \\
108,6\end{array}$ & $\begin{array}{c}78,6 \\
108,6\end{array}$ & $\begin{array}{l}77,1 \\
77,1\end{array}$ & $\begin{array}{l}65,1 \\
65,1\end{array}$ & $\begin{array}{c}34,8 \\
-\end{array}$ \\
\hline 11 & $\begin{array}{l}\text { Масса, кг: } \\
\text { - магнитопровода, включая массу бойка } \\
\text { - ударного узла без инструмента }\end{array}$ & $\begin{array}{c}1,80 \\
3,9\end{array}$ & $\begin{array}{c}1,60 \\
4,1\end{array}$ & $\begin{array}{c}1,60 \\
4,3\end{array}$ & $\begin{array}{l}1,10 \\
2,8\end{array}$ & $\begin{array}{l}1,10 \\
2,7\end{array}$ & $\begin{array}{l}0,57 \\
1,14\end{array}$ \\
\hline 12 & $\begin{array}{l}\text { Приведенная поверхность охлаждения } \\
\text { магнитопровода, } \times 10^{-6} \mathrm{M}^{2}\end{array}$ & 116,4 & - & - & - & - & - \\
\hline 13 & $\begin{array}{c}\text { Средний тепловой поток, } \times 10^{3} \mathrm{BT} / \mathrm{M}^{2} \text { : } \\
\text { - отнесенный к поверхности } \\
\text { охлаждения катушки } \\
\text { - отнесенный к поверхности } \\
\text { охлаждения магнитопровода }\end{array}$ & $\begin{array}{l}24,7 \\
16,3\end{array}$ & $\begin{array}{l}9,7 \\
- \\
\end{array}$ & $\begin{array}{r}10,0 \\
- \\
\end{array}$ & $\begin{array}{r}16,0 \\
- \\
\end{array}$ & $\begin{array}{r}12,9 \\
- \\
\end{array}$ & $\begin{array}{r}15,4 \\
- \\
\end{array}$ \\
\hline 14 & $\begin{array}{l}\text { Средняя удельная тепловая нагрузка, } \\
\times 10^{3} \text { Вт/м³: } \\
\text { - катушки рабочего хода } \\
\text { - катушки обратного хода }\end{array}$ & $\begin{array}{l}1728 \\
1728\end{array}$ & $\begin{array}{l}2385 \\
1722\end{array}$ & $\begin{array}{l}2457 \\
1777\end{array}$ & $\begin{array}{l}1783 \\
1783\end{array}$ & $\begin{array}{l}2112 \\
2112\end{array}$ & $\begin{array}{c}5172 \\
-\end{array}$ \\
\hline 15 & $\begin{array}{l}\text { Постоянная времени нагрева катушки, с: } \\
\text { - рабочего хода: } \\
\text { - обратного хода: }\end{array}$ & $\begin{array}{l}1190 \\
1190\end{array}$ & $\begin{array}{l}290 \\
290\end{array}$ & $\begin{array}{l}290 \\
290\end{array}$ & $\begin{array}{l}220 \\
220\end{array}$ & $\begin{array}{l}160 \\
160\end{array}$ & $\begin{array}{l}75 \\
-\end{array}$ \\
\hline 16 & $\begin{array}{l}\text { Коэффициент теплоотдачи } \\
\text { (приближенный) }\end{array}$ & 25,0 & 35,0 & 35,0 & 50,1 & 40,4 & 85,0 \\
\hline 17 & Схема системы охлаждения & рис. 1 & рис. 3 & рис. 3 & рис. 3 & рис. 4 & рис. 5 \\
\hline
\end{tabular}




$$
q_{v}=\frac{Q}{V_{\mathrm{M}}}
$$

Для характеристики интенсивности процесса нагрева используем постоянную времени нагрева катушки:

- без учета влияния отдачи тепла стали

$$
T_{\mathrm{H}}=\frac{c_{\mathrm{M}} G_{\mathrm{M}}}{k_{\mathrm{T}} S_{\mathrm{K}}},
$$

где $c_{\mathrm{M}}-$ удельная теплоёмкость меди катушки, Дж / кг $\times{ }^{\circ} \mathrm{C} ; G_{\mathrm{M}}-$ масса меди катушки, кг;

- с с учетом влияния отдачи тепла стали

$$
T_{\mathrm{H}}=\frac{c_{\mathrm{M}} G_{\mathrm{M}}+\beta c_{\mathrm{cT}} G_{\mathrm{cT}}}{k_{\mathrm{T}} S_{\mathrm{K}}}
$$

где $c_{\mathrm{CT}}$ - удельная теплоемкость стали магнитной системы, Дж/кг $\times{ }^{\circ} \mathrm{C} ; G_{\mathrm{CT}}-$ масса стали магнитопровода, кг; $\beta$ - безразмерный коэффициент, учитывающий степень передачи тепла от катушки к стали: для бескаркасных катушек с намоткой на втулку $\beta=0,275 \ldots 0,55$, для бескаркасных бандажированных катушек и каркасных катушек $\beta=0,275 \ldots 0,45$ [16].

Использование показателей, отражающих совокупность определенных качеств рассматриваемых систем, позволяет количественно оценить системы охлаждения и выявить наиболее удовлетворяющую техническим требованиям.

Для класса электромагнитных машин с принудительным воздушным охлаждением (табл. 1) продолжительность включения составляет в среднем ПВ $=60,100 \%$.

Среднее значение теплового потока, отнесенного к поверхности охлаждения катушки, изменяется в пределах 9,7...22,2 кВт/м² , что примерно в 1,8 раза выше, чем для машин с естественным способом охлаждения.

Применение принудительной системы охлаждения позволяет существенно увеличить среднюю удельную тепловую нагрузку активного объёма катушки, которая изменяется в пределах $1728 \ldots 5172$ кВт/м³. Это более чем в $3 . .5$ раз выше, чем для систем с естественным способом охлаждения.

Для рассматриваемого класса машин мощность двигателя для систем вентиляций, обеспечивающих коэффициент теплоотдачи $k_{\mathrm{T}}=25 \ldots 35 \mathrm{BT} / \mathrm{M}^{2} \cdot{ }^{\circ} \mathrm{C}$, составляет в среднем не более $6 \%$ от мощности, потребляемой ударным узлом. Этого вполне достаточно, чтобы обеспечить режим работы с ПВ $=60 \%$. Для систем вентиляций, обеспечивающих продолжительный режим работы ударного узла (ПВ = $100 \%$ ), коэффициент теплоотдачи для которых находится в пределах $k_{\mathrm{T}}=50 \ldots 100 \mathrm{BT} / \mathrm{M}^{2} \cdot{ }^{\circ} \mathrm{C}$, для поддержания необходимой производительности мощности ударным узлом.

Таким образом, для поддержания режима работы ударной машины с ПВ $=100 \%$ увеличение ее мощности на каждые 4...6 Вт должно сопровождаться увеличением мощности двигателя вентилятора приблизительно на 1,0 Вт.

Это означает, что при создании электромагнитной машины, например, с энергией удара 100 Дж при 1500 уд/мин и КПД ударного узла 40 \% потребляемая им мощность составит 
6,25 кВт. Следовательно, для обеспечения режима работы с ПВ = 100 \% для отвода теплового потока требуемая мощность двигателя вентиляционной установки должна составлять $1,0 \ldots 1,5$ кВт. Для режима работы с ПВ = 60 \% мощность двигателя вентиляционной установки может быть снижена примерно до 0,4 кВт.

При отводе тепла от катушки путем принудительного охлаждения частичная передача тепла стали магнитопровода через слой изоляции и воздуха, отделяющий от катушки, несущественно оказывает влияние на постоянную времени нагрева. Поэтому расчет постоянной времени нагрева катушки для электромагнитных машин с принудительным воздушным охлаждением выполнен без учета передачи тепла стальным элементам магнитопровода.

Для систем с принудительным воздушным охлаждением постоянная времени нагрева катушки варьируется в диапазоне значений $1,25 \ldots 19,8$ мин.

Следует отметить, что приведенные в табл. 1 расчетные данные не гарантируют точных значений постоянной времени нагрева, так как распределение охлаждающей среды между сосредоточенными и распределенными источниками тепловыделения, порождающие тепловые потоки в электромагнитной машине, в общем случае не представляется возможным. Наиболее точным методом определения взаимного влияния взаимодействующих тепловых потоков в электромагнитной машине ударного действия является эксперимент.

\section{3. Заключение}

1. Выполнена классификация и дана оценка конструктивного совершенства систем принудительного охлаждения синхронных электромагнитных машин ударного действия.

2. Установлено, что среднее значение теплового потока, отнесенного к поверхности охлаждения катушки, для систем с принудительным воздушным охлаждением составляет $9,7 \ldots 22,2 \mathrm{BT} / \mathrm{M}^{2}$.

3. Для систем с принудительным воздушным охлаждением средняя удельная тепловая нагрузка активного объёма, занятого катушкой, составляет $1728 \ldots 5172$ кВт/м ${ }^{3}$.

4. Показано, что принудительное воздушное охлаждение позволяет дополнительно нагрузить электромагнитный ударный узел и тем самым повысить единичную энергию удара при допустимом нагреве в соответствии с требованиями, предъявляемыми к ударной нагрузке электромагнитной машины.

5. Для поддержания режима работы электромагнитной ударной машины с ПВ $=100 \%$ мощность вентиляционной установки может составлять до 25 \% от мощности, потребляемой ударным узлом.

\section{Список литературы}

[1] Нейман Л.А. // Науч. вестн. НГТУ. Новосибирск: Изд-во НГТУ, 2013. № 4. C. $177-183$.

[2] ГОСТ 8865-93. Системы электрической изоляции. Оценка нагревостойкости и классификация. Введ. 1995-01-01. М.: ИПК Изд-во стандартов, 1995. 8 с.

[3]. Нейман Л.А. // Изв. вузов. Электромеханика. 2013. № 6. С. 58-61.

[4]. Нейман Л.А., Скотников А.А. // Научные проблемы транспорта Сибири и Дальнего Востока. 2012. № 2. С. 319-322. 
[5]. Нейман Л.А., Скотников А.А., Нейман В.Ю. // Известия вузов. Электромеханика. 2012. № 6. C. $50-54$.

[6] ГОСТ 12434-83. Аппараты коммутационные низковольтные. Общие технические условия. Введ. 1985-01-01. М.: ИПК Изд-во стандартов, 1988. 25 с.

[7] Удлер Э.И., Шлёнкин О.Г. // Электрические линейные двигатели. Новосибирск: ИГД СО АН СССР, 1972. С. 115-123.

[8] Шлёнкин О.Г., Мирошниченко А.Н. и др. // Электрические ударные машины. Новосибирск: Наука. Сиб отд-ние, 1969. С. 132-145.

[9] Антонов А.Н., Ряшенцев Н.П. // Исследование электрических машин возвратнопоступательного движения. Ч. 1. Новосибирск: ИГД СО АН СССР, 1969. С. 115-121.

[10] Патент РФ № 2502855 Е21B 1/22 Электромагнитный ударный механизм / Л.А. Нейман, В.Ю Нейман, О.В., Е.Ю. Артебякина, А.А. Скотников, НГТУ.; Заявка № 2012114361/03; завл. 11.04.2012 / Опубл. 27.12.2013, Бюл. № 36.

[11]. Патент РФ № 111799 B25D 13/00 Электромагнитная машина ударного действия / В.Ю Нейман, А.А. Скотников, Л.А. Нейман, НГТУ. Заявка № 2011128342/02; завл. 08.07.2011 / Опубл. 27.12.2011, Бюл. № 36.

[12]. Патент РФ № 2496214 Н02К 33/12, F16F 7/104 Синхронный электромагнитный двигатель возвратно-поступательного движения / Л.А. Нейман, В.Ю. Нейман, А.А. Скотников, НГТУ. - Заявка № 2012100472/07; завл. 10.01.2012; опубл. 20.07.2013, Бюл. № 20. Опубл. 20.1.2013 Бюл. № 29. Дополнительно: приоритет от 10.01.2012.

[13] Ряшенцев Н.П., Угаров Г.Г. и др. Электропривод с линейными электромагнитными двигателями. Новосибирск: Наука. Сиб. отд-ние, 1981. 151 с.

[14] Ряшенцев Н.П., Угаров Г.Г., Львищьын А.В. Электромагнитные прессы. Новосибирск: Наука. Сиб. отд-ние, 1989. 216 с.

[15] Мошкин В.И., Нейман В.Ю., Угаров Г.Г. Импульсные линейные электромагнитные двигатели. Курган: Изд-во Курганского гос. ун-та, 2010. 220 с.

[16] Гордон А.В., Сливинская А.Г. Электромагниты постоянного тока. М.-Л.: Госэнергоиздат, $1960.447 \mathrm{c}$. 